\title{
How Positive Are Recent Employment and Labor Market Trends?
}

\author{
Richard G. Anderson, Vice President and Economist
}

$\mathrm{T}$ he Bureau of Labor Statistics (BLS) publishes two streams of data regarding U.S. labor markets. ${ }^{1}$ One is the establishment survey that collects payroll employment figures from firms. The other is the household survey that infers total employment and labor force figures from a battery of survey questions asked of households. ${ }^{2}$ Both have shortcomings.

Because the payroll survey counts the number of jobs, persons with more than one job are counted more than once. The household survey avoids double-counting and also includes the self-employed, but its accuracy depends on the honest responses of households. The total labor force, equal to the number of persons employed plus the number unemployed who are seeking employment, is measured from the household survey. The unemployment rate is also calculated from the household survey data as the following ratio:

(Total labor force - Total employment)/Total labor force.

Assessing the state of the economy requires estimates of the trends in employment, labor force, and unemployment. Large month-to-month fluctuations make it difficult to infer changes in longer-run trends from monthly data. The figures for July and August illustrate the issue: The closely watched "total nonfarm payroll employment" (establishment survey) increased 141,000 and 96,000 during July and August, respectively; but total employment in the household survey decreased, respectively, by 195,000 and 119,000. The labor force also decreased, respectively, by 150,000 and 368,000 . As a result, the measured unemployment rate increased from 8.2 percent to 8.3 percent in July and decreased from 8.3 percent to 8.1 percent in August.

Growth in the labor force and employment reflects three factors, two of which primarily affect the long-run: growth of the total population and changes in its age composition. Near-term growth reflects these factors plus an additional one-whether the unemployed decide to seek work. Historical data show that the labor force tends to shrink when economic activity weakens (because unemployed persons cease to seek employment) and to expand when economic activity strengthens. As shown in the first chart, labor force growth did not rebound after the most recent recession. Recent data suggest that growth might have returned: Since January 2012, the labor force has been larger year-over-year by approximately 1 million or more persons each month. The BLS predicts that the labor force will increase 6.8 percent, or by 10.5 million persons, from 2010 to 2020 , slightly slower than during 2000-10, when the labor force increased 7.9 percent, or by 11.3 million persons (Toossi, 2012).

A tool that clarifies labor force growth is the participation rate, defined as the ratio of the labor force to the working-age population (16 years of age and older). As shown in the second chart, the participation rate peaked at 67.1 percent in 2000 due, in part, to increased labor market participation of older workers. Contrary to historical patterns, the rate did not increase after the 2000 recession but, instead, has trended downward (with a leveling off during 2005-08); the BLS projects that the participation rate will be 62.5 percent in 2020. The aging of the work force increases uncertainty regarding projections of the participation rate. The oldest of the "Baby Boom" generation (born from 1946 to 1964) reached age 55 in 2001coincidentally, a year when labor force growth slowed during an economic recovery. By 2020, workers age 55 and older are projected to be more than 36 percent of the labor force. The participation rate of workers age 55 and older has increased steadily in recent years, from 30.1 percent in 1990 , to 32.4 percent in 2000, to 40.2 percent in 2010, and the BLS projects that it will increase to 43 percent in 2020; yet, news reports suggest that unemployed older workers are facing increased difficulty in finding employment. ${ }^{3}$ At the same time, the BLS projects that the participation rate for workers age 25 to 54 will decrease to 81.3 percent in 
2020 , versus 82.2 percent in 2010 and 84.0 percent in 2000 . If the participation of older workers diminishes during the decade (similar to that of younger workers), then labor force growth and the increase in employment necessary to regain full employment will be corresponding smaller.

In summary, recent data suggest that labor markets continue to improve. Labor force growth resumed in early 2012 after a more than three-year hiatus, likely reflecting both stronger employment growth and increased optimism among the unemployed. Yet, the aging of the population suggests a further long-run decrease in the participation rate and, in turn, a lower long-run trend in employment growth.

\section{Notes}

1 The household survey is part of the Current Population Survey; see http://www.census.gov/cps/. The establishment survey is officially known as the Current Employment Statistics program; see http://www.bls.gov/ces/.

2 The BLS publishes the original figures and figures adjusted for seasonal fluctuations. Figures in this essay are seasonally adjusted.

${ }^{3}$ This observation, and increases in the number of long-term unemployed, have generated controversy regarding the mixture of "structural" versus "cyclical" unemployment; see for example Lazear and Spletzer (2012).

\section{References}

Edward P. Lazear and James R. Spletzer, "The United States Labor Market: Status Quo or A New Normal?" Presented at the Federal Reserve Bank of Kansas City Jackson Hole Symposium, September 1, 2012; http://www.kansascityfed.org/publicat/sympos/2012/ el-js.pdf.

Mitra Toossi, "Labor Force Projections to 2020: A More Slowly Growing Workforce." Monthly Labor Review, January 2012, pp. 43-64.

\section{Year-Over-Year Change in Civilian Labor Force}

Millions of Persons

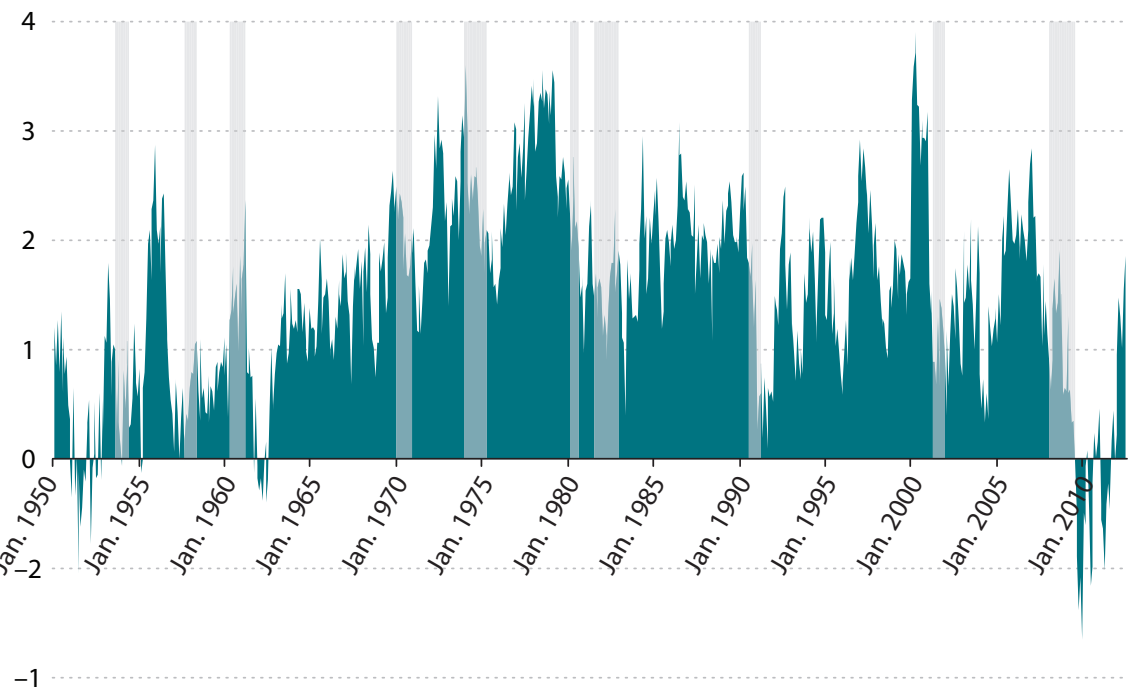

NOTE: Because year-over-year changes are shown, data are not seasonally adjusted. Shaded areas indicate recessions as determined by the National Bureau of Economic Research.

SOURCE: Bureau of Labor Statistics / FRED (Series ID: LNU01000000).

\section{Civilian Labor Force Participation Rate}

Percent

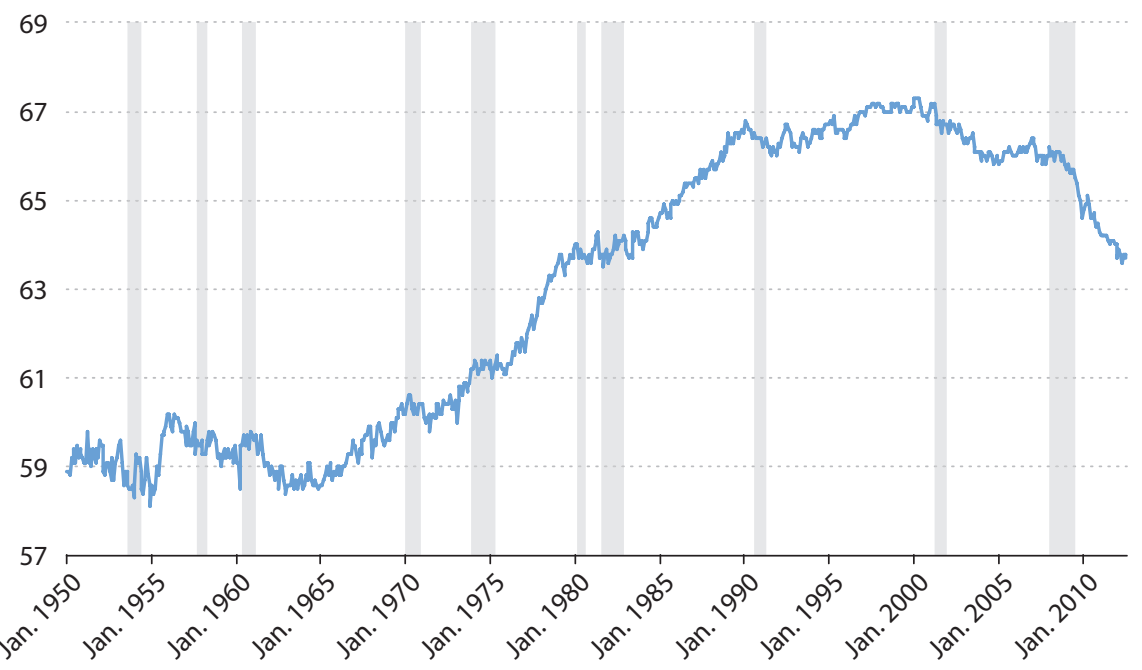

NOTE: Data are seasonally adjusted. Shaded areas indicate recessions as determined by the National Bureau of Economic Research.

SOURCE: Bureau of Labor Statistics / FRED (Series ID: CIVPART). 